\title{
Resolução Anafórica e Foco do Discurso: O Caso do Pronome Demonstrativo Francês "Híbrido" Este (celui-ci)
}

\author{
Marion Fossard ${ }^{123}$ \\ Dominique Cardebat \\ Jean-Luc Nespoulous \\ Universidade de Toulouse-Le Mirail, França
}

\begin{abstract}
Resumo
Na tradição da teoria da centralização, muitos estudos mostraram uma sensibilidade significativa dos pronomes anafóricos para se referir às entidades focalizadas na representação do discurso. Essa sensibilidade estaria ausente nas expressões explícitas e nos substantivos repetidos. De acordo com os princípios dessa teoria, apresentamos um experimento com o objetivo de estudar a função referencial de identificação de uma expressão híbrida, o pronome demonstrativo "este". Os resultados indicam que a utilização dessa expressão está fortemente restringida pelas entidades de focalização e estaria motivada a estabelecer o centro de atenção sobre uma entidade mediamente focalizada. Esses resultados são discutidos à luz da teoria da centralização. Palavras-chave: Teoria da centralização; resolução anafórica; foco do discurso; pronome demonstrativo.
\end{abstract}

Anaphoric Resolution and Discourse Focus:

The Case of the French "Hybrid" Demonstrative Pronoun (celui-ci)

\begin{abstract}
In the tradition of centering theory, many studies have shown a significant sensitivity of anaphoric pronouns to refer to focus entities in a discourse representation. This sensitivity would be absent with more explicit expressions like the repeated nouns. According to the principles of this theory, we present an experiment aiming at studying the function of the referential identification of a hybrid expression: the demonstrative pronoun celui-ci. The results indicate that the use of this expression is strongly constrained by the entities of focalization and it would be motivated to establish the center of attention on a mild focus entity. These results are discussed in the light of centering theory.

Keywords: Centering theory; anaphoric resolution; discourse focus; demonstrative pronoun.
\end{abstract}

Um discurso não é apenas uma simples seqüência de enunciados sucessivos. Um discurso é coerente quando integra seus enunciados formando uma estrutura. Desta forma, o modo como os enunciados referem-se a entidades comuns em um discurso influencia e determina a sua coerência. A pesquisa e a identificação dos fatores que permitem um sujeito compreender e perceber uma seqüência de enunciados como uma mensagem coerente torna-se um dos grandes desafios das teorias sobre a estrutura e a interpretação do discurso.

Entre os fatores em jogo, existe um grande consenso relacionado à referência anafórica. Pronomes, nomes repetidos, descrições definidas etc. são expressões

\footnotetext{
1 Endereço para correspondência: Laboratoire de Neuropsycholinguistique Jacques Lordat. Maison de la Recherche, Université de Toulouse-Le Mirail. 5, allées, Antonio Machado. 31058. Toulouse CedexFrance Fone: (05) 615035 98, Fax: (05) 614918.

${ }^{2}$ Versão ao português realizada por: Maria Pullen Parente (Curso de Lingüística da USP) e Maria Alice de Mattos Pimenta Parente (Instituto de Psicologia UFRGS).

${ }^{3}$ Unité INSERM 455. CHU Purpan-Toulouse. Fone: (5) 61779500.
}

referenciais que têm um papel importante na coerência do discurso e na manutenção da coesão do texto, permitindo ao leitor (ou ouvinte) estabelecer as relações entre os diferentes enunciados percebidos. A função principal destes marcadores não é somente evitar uma repetição formal que torna difícil a continuidade referencial do discurso; mas também, em relação aos pronomes (anafóricos), assegurar uma função de tematização (Karmiloff-Smith, 1981), enquanto que as redenominações (no caso das repetições nominais) parecem agir indicando principalmente uma mudança na continuidade referencial (Kleiber, 1994).

Vários estudos colocaram em evidência que a utilização de um pronome anafórico para designar uma entidade saliente - ou seja, o tópico no discurso - traz um índice explícito, mostrando que o enunciado atual está relacionado com o contexto estabelecido, enquanto que o emprego de uma expressão mais informativa, como um substantivo, torna essa relação mais difícil de inferir (Chambers \& Smyth, 1998; Gordon, Gorsz \& Gilliom, 1993; Hudson, D’Zmura \& Tanenhaus, 1998). 
A teoria de centralização (Centering Theory, 1995, 1998), constantemente citada nos estudos sobre as relações existentes entre as anáforas (os anafóricos), propõe que a estrutura do enunciado e a coerência discursiva têm por objetivo "dirigir o foco de atenção para a escolha de uma expressão referencial e para a coerência dos enunciados dentro do segmento de um discurso" (Gross, Joshi \& Weinstein, 1995, p. 204). Recentemente utilizada nas pesquisas psicolingüísticas sobre a compreensão do discurso, a teoria de centralização também foi usada nos modelos de resolução de anáforas.

Esta teoria postula que cada enunciado com coerência local dentro do discurso está relacionado com elementos atencionais denominados centros. Dois tipos de centros são postulados: (1) centros antecipatórios (Ca), que correspondem ao conjunto de unidades semânticas evocadas através de um enunciado dado, e (2) um único centro retroativo $(\mathrm{Cr})$, que corresponde a um membro do Ca que será retomado no próximo enunciado.

Os membros do Ca constituem, desta forma, um conjunto de referentes potenciais dos quais pode-se predizer, com diferentes probabilidades, que se tornarão o tópico dos enunciados posteriores (i.e.: Cr). Estes referenciais são parcialmente ordenados em termos de proeminência ou de saliência atencional, ou seja, em função de sua probabilidade relativa em figurar como o $\mathrm{Cr}$ do enunciado seguinte. O primeiro elemento classificado no conjunto de centros de $\mathrm{Ca}$ denomina-se centro preferencial (Cp).

Os parâmetros estabelecidos pela centralização para determinar o nível de saliência relativa dos membros de Ca são de ordem formal. Os argumentos experimentais foram relatados por Gordon e colaboradores (1893), apontando uma proeminência relacionada à função sintática e à ordem linear da introdução (uma evocação precedente é mais importante do que uma evocação subseqüente). Portanto, a ordenação dos membros de Ca segue a ordem do mais acessível ao menos acessível da seguinte forma: sujeito $>$ objeto indireto animado $>$ objeto direto $>$ objeto indireto inanimado $>$ objeto oblíquo ${ }^{4}$. Esta ordem tem duas conseqüências importantes: de um lado, ela influencia a probabilidade

\footnotetext{
${ }^{4} \mathrm{O}$ termo objeto oblíquo é utilizado na teoria da centralização para designar as demais funções gramaticais que não são classificadas, como sujeito, objeto direto, objeto indireto. Ele significa que o objeto em questão é periférico em relação ao predicado. Nos experimentos descritos nesse trabalho, no segmento $2 \mathrm{~b}$ da Tabela 1 , ALICE sendo uma entidade fracamente focalizada, assume a função de objeto oblíquo (na posição objeto de uma preposição dentro de um sintagma nominal objeto direto). Por outro lado, no segmento 2a da mesma Tabela, ALICE corresponde a uma entidade focalizada (sujeito sintático + menção inicial).
}

que uma entidade seja retomada como $\mathrm{Cr}$ do enunciado seguinte; de outro, ela afeta a interpretação dos pronomes (Gordon \& Hendrick, 1998).

Certo número de estudos (Gordon e cols., 1993, Gordon \& Chan, 1995, Hudson, D’Zmura e cols. 1998) também mostrou um efeito de penalidade do substantivo repetido (evidenciado pelo aumento do tempo de leitura) que aparece quando o $\mathrm{Cr}$ (objeto de discurso psicologicamente mais saliente) é realizado por um nome repetido, ao invés de um pronome anafórico. Essa penalidade torna-se ainda mais relevante quando a entidade retomada ocupa uma posição sintaticamente importante no enunciado precedente (i.é. o sujeito gramatical).

Salientada por inúmeros autores, a função essencial dos pronomes anafóricos - e de outras expressões reduzidas - seria a de designar as entidades que foram mencionadas em um discurso e que são focalizadas, salientadas, na representação do discurso. Ao contrário, a função essencial dos substantivos - e de outras expressões plenas - seria principalmente introduzir entidades nas representações do discurso. De fato, os nomes são freqüentemente empregados para fazer referência a entidades fragilmente focalizadas.

Em resumo, os pronomes seriam imediatamente interpretados como se referindo a entidades discursivas previamente mencionadas, enquanto que os substantivos repetidos exigiriam tratamentos mais elaborados (Garrod, Freudenthal \& Boyle, 1994).

Uma série de estudos realizados por Sanford, Moar e Garrod (1988) também mostrou que o tratamento de expressões anafóricas era mais rápido quando estas designavam entidades focalizadas (realizadas por meio de um nome próprio) do que quando designavam entidades fragilmente focalizadas (realizadas através de um substantivo comum), desde que as anáforas empregadas fossem pronomes. Já com referência ao emprego de um substantivo repetido, nenhuma diferença foi constatada.

Nesse breve apanhado teórico surge um fato importante: diferentemente dos substantivos ou de sintagmas nominais plenos, os pronomes anafóricos têm uma tendência a designar entidades que são focalizadas nas representações do discurso. Eles seriam, portanto, indicadores mais sensíveis de focalização de entidades do que os substantivos.

Os resultados de nossas próprias experiências (Fossard, 1999) confirmam este fato. Utilizamos dois tipos de expressões referenciais empregadas nos experimentos realizados a partir da teoria da centralização - o pronome anafórico "ele" e o nome próprio repetido - e variamos 
a focalização de entidades dentro de um discurso, segundo o ordenamento proposto pela centralização (Tabela 1). Os resultados obtidos indicaram que (1) a referência a uma entidade focalizada melhora nitidamente o tempo de tratamento da informação e (2) o emprego de um pronome, para se referir a uma entidade focalizada, é mais coerente, mais evidente (tempo de leitura mais rápido), do que o emprego de substantivos repetidos (efeito de penalidade de substantivo repetido). Os resultados obtidos mostraram, igualmente, que um pronome anafórico recebe uma marca de um referente que se mantém ativo e focalizado (tempo de leitura significativamente mais rápido quando o pronome designa a entidade focalizada, ao invés da entidade não focalizada). Ao contrário, o substantivo repetido não é marcado pelo estado de ativação de seu referente. Em outras palavras, apesar do substantivo repetido ser mais conveniente do que um pronome para se referir a uma entidade menos focalizada, não se notam diferenças significativas se o substantivo repetido referir-se a uma entidade focalizada ou a uma entidade fragilmente focalizada. expressão referencial realizada como um nome próprio tem menos necessidade de ser uma continuidade da situação inicial.

Assim, a partir dessa fragilidade (relativa) da sensibilidade do substantivo repetido para a focalização das entidades discursivas, um novo estudo foi planejado. Empregou-se um marcador mais específico do que o substantivo repetido, o pronome anafórico-dêitico "este" (Kleiber, 1994). O objetivo desse novo estudo foi evidenciar a forte especialização desse marcador na preferência de uma entidade não focalizada.

Uma abordagem textual clássica faz uma oposição entre anáfora e deixis, tomando como base os contextos textuais e extralingüísticos. Nessa abordagem: (1) uma expressão é anafórica quando seu referente encontra-se no contexto lingüístico, mas (2) uma expressão é dêitica quando seu referente encontra-se na situação extralingüística. A partir do início dos anos 90, uma nova abordagem para a oposição anáfora/deixis, tomou por base processos cognitivos de memorização. Nesta ótica, (1) uma expressão é anafórica quando retorna à uma entidade já conhecida, ou que já tem seu lugar no universo

Tabela 1. Segmentos Lingüísticos Apresentados no Experimento de Fossard (1999)

\begin{tabular}{lll}
\hline Segmentos & Estímulos & Tarefas \\
\hline 1 & $\begin{array}{l}\text { Os patrões da usina faziam uma grande } \\
\text { reunião } \\
\text { Alice (i) exigia um relatório de Ricardo } \\
\text { para (i) dar uma opinião }\end{array}$ & Leitura \\
2a (entidade focalizada) & $\begin{array}{l}\text { Ricardo (i) exigia um relatório de Alice } \\
\text { para (i) dar uma opinião. }\end{array}$ & Leitura \\
2b (entidade focalizada) & Durante uma hora ela falava sem parar & Leitura \\
$3 \mathrm{a}$ (pronome) & $\begin{array}{l}\text { Durante uma hora Alice falava sem } \\
\text { parar } \\
\text { A mulher é tagarela }\end{array}$ & Leitura \\
Afirmação & J mulgamento (verdadeiro/falso)
\end{tabular}

Confirma-se, portanto, que o pronome anafórico, contrariamente ao substantivo repetido, é um indicador sensível da focalização das entidades. Em resumo, se o pronome manifesta uma dependência ao foco do discurso (i.é. na focalização das entidades), o substantivo repetido é indiferente a esse tipo de influência. Numerosos argumentos (Garrod e cols., 1994; Gordon e cols., 1993) indicam, por outro lado, que o substantivo repetido rompe a coerência local do discurso no sentido em que é interpretado em relação à coerência global do discurso, uma vez que não fornece uma contribuição importante à coerência local. De qualquer forma, o enunciado relacionado à do discurso, ou ainda que já se encontra no locus de atenção do interlocutor; entretanto, (2) uma expressão é dêitica quando introduz um novo referente no foco de atenção. Assim, a anáfora é um processo que faz uma referência a um referente já conhecido pelo interlocutor, enquanto a deixis consiste na introdução de um novo referente ainda não manifestado na memória imediata; portanto, trata-se aqui, de uma oposição que não mais se apóia na localização do referente (dentro ou fora do texto), mas sim na distinção referente conhecido vs referente novo.

Nesse contexto teórico, assim como o pronome anafórico "ele", o pronome demonstrativo "este" constitui 
um marcador indexical (i. é: que indica ao invés de denotar) e, neste sentido, seu emprego deverá evitar a ruptura da coerência local do discurso. Ao contrário da palavra repetida que serve principalmente para introduzir novas entidades na representação do discurso, o pronome "este" deveria ser sensível à focalização de entidades e, desta forma, deveria permitir um acesso rápido a uma entidade medianamente focalizada.

Os experimentos realizados no contexto da teoria da centralização só utilizaram, até o momento, um conjunto muito restrito de expressões referenciais. Somente dois marcadores foram utilizados de forma sistemática: o pronome anafórico e o nome próprio repetido. $\mathrm{O}$ contraste (importante) entre estes dois marcadores não apenas serviu para localizar e precisar a presença de um centro retroativo, cuja prova diagnóstica é a obtenção de um efeito de penalidade da palavra repetida, mas serviu também para justificar o ordenamento dos membros do centro antecipador, que afeta essencialmente a interpretação dos pronomes.

Com esse novo estudo, que visa a estudar o contraste - mais sensível - existente entre o pronome anafórico "ele" e o pronome anafórico-dêitico "este", em relação à focalização das entidades do discurso, o objetivo é testar os princípios da teoria da centralização à luz de um novo marcador (o pronome "este"), e de abordar, especificamente, o papel da focalização de entidades discursivas em relação às expressões referenciais. Em outros termos, se a função do pronome anafórico é "revelar" um foco elevado (cf. os resultados de estudos anteriores), a função do pronome anafórico-dêitico seria "compensar" um foco médio?

\section{Experimento}

De acordo com os princípios da teoria da centralização, o objetivo desse primeiro experimento é estudar os efeitos conjuntos da estrutura do discurso que salienta algumas entidades mais do que outras (cf. o ordenamento do $\mathrm{Ca}$ ) - e de dois marcadores referenciais sobre os processos de tratamento de frases no contexto discursivo. Este experimento visa, portanto, verificar a acessibilidade diferencial de entidades discursivas por meio de diferentes expressões referenciais - o pronome anafórico "ele" vs. o pronome anafórico-dêitico "este" que supostamente têm uma função diferente na identificação de seu referente.

O termo pronome anafórico-dêitico, proposto por Kleiber (1994), pauta-se pela hipótese de que o modo de fixação referencial do pronome "este" pode introduzir um novo referente. Ao referenciar um já introduzido, ele permite focalizar uma mudança temática através de uma operação de isolamento de elementos novos (apresentação do referente em novo quadro discursivo). Esse marcador permitiria, desta forma, mudar o foco de atenção estabelecido, ou seja, ele permitiria mudar a atenção da entidade altamente focalizada, a fim de possibilitar que a entidade medianamente focalizada se tornasse referencialmente saliente.

Ele atuaria, portanto, como um marcador híbrido, anafórico e dêitico (anafórico devido a sua própria forma e dêitico, devido ao seu elemento demonstrativo). Isto o torna uma expressão sui generis quando se tem o objetivo de modificar o foco de atenção. A utilização de "este" causará uma ruptura ou, pelo menos, uma modificação da organização referencial anterior através da separação de um dos referentes mencionados que é retomado deiticamente.

Assim, para aumentar a saliência de um referente que não é o mais focalizado, mas que possui um foco médio, ou seja, que não se encontra dentro do foco de atenção (i.é. um elemento não classificado como sendo primeiro no conjunto de membros do $\mathrm{Ca}$ ), um marcador como "este", cuja utilização obriga um emparelhamento referencial Token - reflexivo ${ }^{5}$, deveria permitir uma mudança de foco do discurso atual (Cornish, 1999) preservando, ao mesmo tempo, a coerência local do discurso.

\section{Método}

\section{Participantes}

Quarenta estudantes, destros, com idade entre 19 e 28 anos, foram testados individualmente. Todos tinham como língua maternal o francês.

\section{Material}

Foram construídos 40 textos experimentais $(+48$ textos equivalentes de mesma extensão). Os textos compostos de três frases são divididos em quatro

\footnotetext{
${ }^{5}$ Expressões token-reflexivas são aquelas que exigem a identificação do referente a partir de sua ocorrência, de seu próprio token. São expressões cujo referente é identificado com a ajuda de elementos do contexto da enunciação. Desta forma, a identificação de um pronome como "este" exige que os interlocutores elaborem um contexto que permita identificar o referente. O valor token-reflexivo de "este" (como no caso de todos demonstrativos) faz com que a identificação do referente parta da ocorrência do demonstrativo e tem como conseqüência a exigência de uma identificação de um referente novo e específico. É este valor tokenreflexivo que permite compreender por que um demonstrativo possibilita uma ruptura com o universo do discurso até então manifestado, ao invés de sua continuação.
} 
condições que refletem um cruzamento das seguintes variáveis: "tipo identidade X tipo de expressão referencial".

Tipo identidade é a entidade do discurso altamente focalizada - entidade 1 - introduzida pelo substantivo próprio em posição de tópico de discurso (menção inicial e função de sujeito) $v$ s entidade de discurso medianamente focalizada - entidade 2 - introduzida pela descrição da função, preenchendo a função gramatical do objeto indireto do verbo.

Expressão tipo referencial é o pronome anafórico "ele" vs. o pronome anafórico-dêitico "este". Nos textos, a primeira frase é uma frase introdutória. A segunda frase apresenta os dois personagens, um em foco mais elevado (entidade 1) e o outro em foco médio (entidade 2). Esses dois personagens são do mesmo gênero: dois homens ou duas mulheres ${ }^{6} \mathrm{~A}$ terceira frase (frase alvo) refere-se a um dos dois personagens, através do pronome "ele" ou do pronome "este". Quando a expressão referencial refere-se à unidade 1, o predicado orienta-se em direção à unidade 1; quando a expressão referencial refere à unidade 2 , o predicado orientase em direção à unidade 2.

Após cada texto, uma questão, relacionada à frase alvo, avalia a compreensão do pronome. Cada questão apresenta uma escolha com duas respostas possíveis (A,
B) e para um mesmo texto, a questão muda conforme o tipo de identidade a que o pronome se refere. A ordem das duas escolhas é contrabalançada entre os textos experimentais e os textos de preenchimento (ver um exemplo na Tabela 2).

\section{Procedimentos}

Utilizamos um plano de cruzamento dos textos com as condições. Os 40 textos experimentais foram agrupados em blocos de dez textos (+ 48 de preenchimento) e os 40 participantes foram agrupados em quatro grupos de dez participantes. Este plano permitiu que cada um dos 40 textos apresentasse as quatro condições de cruzamento, e que cada participante lesse o mesmo texto uma só vez e lesse também o mesmo número de textos das quatro condições.

Os textos foram apresentados em uma tela de computador em ordem aleatória para cada participante. No teclado, somente as teclas "V" e "N" e a barra de espaço eram visíveis. As teclas "V" e "N" foram respectivamente mascaradas pelas letras " $\mathrm{A}$ " e "B" (o que correspondia às duas possibilidades de resposta). A leitura de cada texto era feita em duas etapas, seguida

Tabela 2. Exemplo de um Texto Apresentando as Quatro Condições Experimentais e os Tipos de Resposta.

Tipo de estímulo Exemplo

Texto

Primeira Condição:

Frase alvo (entidade 1 x pronome "ele")

Segunda Condição:

Frase alvo (entidade $1 \mathrm{X}$ pronome "este" )

Terceira Condição:

Frase alvo (entidade $2 \mathrm{X}$ pronome "ele")

Quarta Condição:

Frase alvo (entidade $2 \mathrm{X}$ pronome "este")

Questões relacionadas à entidade 1

Resposta (múltipla escolha)

Questões relacionadas à entidade 2

Resposta (múltipla escolha)
Os alunos da escola ficaram descontrolados durante o recreio.

Maria (entidade 1) deu um pontapé na sua professora (entidade 2) no pátio.

Ela foi severamente punida.

Esta foi severamente punida.

Ela ficou com um grande hematoma.

Esta ficou com um grande hematoma.

Quem foi severamente punida?

A) Maria B) A professora

Quem teve um grande hematoma?

A) Maria B) A professora

${ }^{6}$ Um estudo preliminar mostrou que, para revelar o modo de estabelecimento referencial próprio a um anafórico-dêitico, a variável gênero precisa ser neutralizada (i.é., os possíveis referenciais de mesmo sexo). A ambigüidade quanto ao sexo parece ser necessária para que seja pertinente a utilização do marcador. imediatamente da pergunta. As duas primeiras frases apareciam na tela, depois aparecia a frase alvo e, por fim, a pergunta. Os participantes controlavam a rapidez de apresentação, apoiando sobre a barra de espaço. A ordem 
insistia que os participantes lessem cada frase o mais rapidamente possível, prestando atenção em sua compreensão. Quando apoiavam a barra de espaço, as duas frases desapareciam, para dar lugar à frase seguinte, até a aparição da questão. Havia uma pausa de um segundo entre o último apoio da barra de espaço e a pergunta e os participantes apoiavam sobre uma das teclas de resposta para responder. O tempo de leitura e o tempo de resposta eram gravados pelo computador. Cada participante começava a sessão com um treino antes da experiência. Esta tinha uma duração aproximada de trinta minutos.

\section{Resultados}

\section{Número de Erros e Tempo de Reação (TR) das Perguntas}

O número de erros das questões foi pequeno $(3,5 \%$ de erros em todas as quatro condições). A Tabela 3 apresenta o número de erros e o TR médio obtido (incluindo somente o TR das respostas corretas) para as quatro condições experimentais. entidade" e "tipo de expressão referencial" é significativa $[F 1(1,39)=2,829, p=0,0415 ; F 2(1,39)=5,931, p=0,0196]$. A diferença parcial entre as condições "entidade $1 \mathrm{X}$ pronome ele" e "entidade $1 \mathrm{X}$ pronome este" é significativa $[F 1(1,39)=4,236, p=0,0463 ; F 2(1,39)=5,931$, $p=0,0311]$, assim como a diferença entre as condições "entidade $1 \mathrm{X}$ pronome este" e "entidade $2 \mathrm{X}$ pronome este" $[F 1(1,39)=7,456, p=0,0094 ; F 2(1,39)=7,750$, $p=0,0082]$. Esses dados sugerem que a condição "entidade $1 \mathrm{X}$ pronome este" afasta-se das outras três condições. De fato, o número de erros é bem maior e o tempo de reação mais longo quando o texto é construído nessa condição.

\section{Tempos de Leitura (TL) da Frase Alvo}

Com relação à análise dos tempos de leitura (TL), as análises estatísticas (ANOVAs realizadas com fator sujeito aleatório - plano F1 - e com fator texto aleatório plano F2) referem-se aos TL da frase alvo, ponderandose o número de caracteres, a fim de corrigir os efeitos decorrentes das variações de extensão da frase alvo.

Tabela 3. Taxa de Erros (em \%) e TR Médios (ms) Obtidos nas Quatro Condições Experimentais

\begin{tabular}{|c|c|c|}
\hline & Pronome "ele" & Pronome "este" \\
\hline Entidade 1 & $\begin{array}{c}1,25 \% \\
1651 \quad(285)[272]\end{array}$ & $\begin{array}{l}5,25 \% \\
(376)[376]\end{array}$ \\
\hline Entidade 2 & $\begin{array}{c}2,75 \% \\
1698 \quad(403)[317]\end{array}$ & $\begin{array}{c}3,75 \% \\
1644 \quad(327)[213]\end{array}$ \\
\hline
\end{tabular}

Os dados nos parênteses correspondem ao desvio padrão com fator sujeito aleatório. Os dados entre colchetes correspondem ao desvio padrão com fator texto aleatório.

Apesar de poucos erros, nota-se um efeito das condições no número de erros (Qui quadrado=10,136, $p=0,0174)$. Uma comparação dois a dois revelou, entretanto, que somente a diferença entre a condição "entidade $1 \mathrm{X}$ pronome este" foi significativa (Qui quadrado $=9,54 p=0,002)$. As condições relativas aos textos elaborados na condição "entidade $1 \mathrm{X}$ pronome este" foram mais difíceis do que as outras. Não é de se surpreender pois esta condição é realmente a mais difícil. A utilização do marcador "este" para se referir a uma entidade altamente focalizada é extremamente pouco habitual, e a coerência do texto fica sensivelmente alterada.

O mesmo padrão é encontrado no tempo de reação (TR). As análises de variância realizadas com o fator sujeito aleatório (plano F1) e com o fator texto aleatório (plano F2), indicam que a interação entre os fatores "tipo de
A Figura 1 apresenta os TL médios ponderados (ms) da frase alvo, correspondentes às quatro condições experimentais.

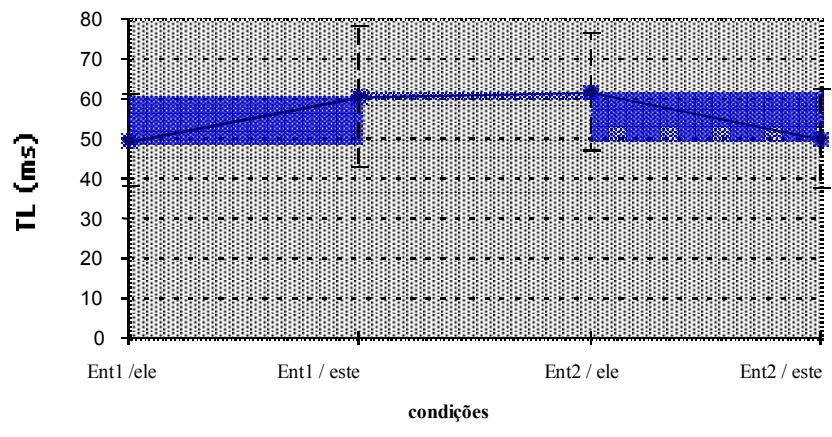

Figura 1. Resultados dos tempos de leitura para os pronomes ële"e ëste"nas duas entidades 
As análises de variância não revelaram um efeito principal do fator "tipo de entidade" $[F 1(1,39)=0,374$, $p=0,5446 ; F 2(1,39)=0,098, p=0,7562]$, nem efeito principal do fator "tipo de expressão referencial" $[F 1(1,39)=0,212, p=0,6479 ; F 2(1,39)=0,234, p=0,6316]$. Isto indica que qualquer que seja a expressão referencial utilizada, as frases alvo que se referem à entidade 1 (TL médio $=55 \mathrm{~ms}$ ) não são tratadas mais rapidamente do que as que referem à entidade 2 (TL médio $=55,8 \mathrm{~ms}$ ). De mesma forma, quando não se considera o tipo de entidade a que a frase alvo se refere, não se constata nenhuma diferença significativa entre as frases relativas aos pronomes anafóricos (Tlmédio $=55,6 \mathrm{~ms}$ ) e aquelas relativas aos pronomes anafóricos-dêiticos (Tlmédio $=55,2 \mathrm{~ms}$ ).

Resumindo-se, considerar a focalização das entidades independentemente dos marcadores de repetição utilizados (e vice versa) não dá nenhum indício (Figura 2): um sem o outro não traz nenhuma contribuição significativa para o tratamento da frase; sua interação, ao contrário, é significativa $[F 1(1,39)=41,108, p=0,001$; $F 2(1,39)=122,880, p=0,0001]$.

Com relação à focalização das entidades, as frases alvo que se referem a uma entidade altamente focalizada (entidade 1) foram tratadas mais rapidamente com o pronome anafórico (TL médio $=49,6 \mathrm{~ms}$ ) do que com o pronome anafórico-dêitico (TL médio $=60,5 \mathrm{~ms}$ ). A

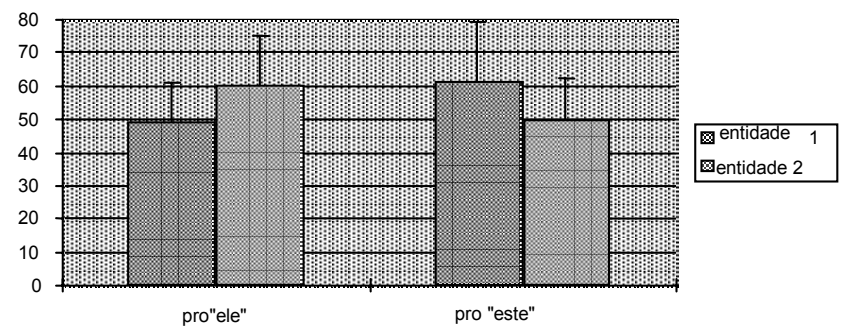

Figura 2. Médias dos tempos de leitura na referenciação das duas entidades pela utilização do pronome "ele" e do pronome "este"

diferença entre as duas condições é significativa $[F 1(1,39)=25,293, \quad p=0,0001 ; \quad F 2(1,39)=79,352$; $p=0,0001]$. Por outro lado, as frases alvo que se referem à entidade focalizada medianamente (entidade 2) foram tratadas mais rapidamente com um pronome anafóricodêitico (TL médio $=49,8 \mathrm{~ms}$ ) do que com um pronome anafórico (TL médio $=61,7 \mathrm{~ms}$ ). A diferença desta última comparação também foi significativa $[F 1(1,39)=36,762$, $p=0,0001 ; F 2(1,39)=53,248, p=0,0001]$. Esses resultados estão a favor de um acesso seletivo de tipos de entidades (mais ou menos focalizadas) por diferentes expressões referenciais.
Com relação às expressões referenciais, as frases alvo que utilizam um pronome anafórico são tratadas mais rapidamente quando o pronome se refere à entidade 1 , do que quando se refere à entidade 2. Esta diferença foi significativa $[F 1(1,39)=42,143, p=0,0001 ; F 2(1,39)=18,173$, $p=0,0001]$. Por outro lado, as frases alvos que utilizam um pronome anafórico-dêitico são tratadas mais rapidamente quando esse pronome se refere à entidade 2 , do que quando ele se refere à entidade 1 . Também aqui a diferença é significativa $[F 1(1,39)=19,714, p=0,0001 ; F 2(1,39)=23,017$, $p=0,0001]$. O pronome anafórico-dêitico aparece também como sendo marcado para estado de ativação de seu referente; seu papel seria o de compensar um foco médio.

\section{Discussão}

Os resultados obtidos colocam em evidência, de forma clara, uma função de identificação diferencial dos marcadores estudados (o pronome anafórico "ele" vs o pronome anafórico dêitico "este"), conforme o tipo de entidade repetida. Esses dois marcadores, cujo traço comum parece ser sua sensibilidade à focalização das entidades discursivas, manifesta-se a partir de um princípio regulador, (i.é. a focalização), um comportamento referencial "oposto". Isto é mostrado por dois índices: o índice da preferência do marcador (i.é. para um mesmo marcador - pronome anafórico ou pronome anafórico-dêitico - qual seria a entidade preferida?) e o índice de preferência de entidade (i.é: para uma mesma entidade - entidade 1 ou entidade 2 - qual seria o marcador preferido?). O pronome anafórico proporciona um acesso rápido tanto para a entidade mais focalizada (entidade 1) como para a entidade mediamente focalizada (entidade 2), e a entidade altamente focalizada é mais rapidamente acessada pelo pronome anafórico do que pelo pronome anafórico-dêitico. Por outro lado, uma entidade mediamente focalizada é, por sua vez, mais rapidamente acessada pelo pronome anafórico-dêitico do que pelo pronome anafórico.

Para cada um dos dois marcadores estudados, notase, portanto, uma convergência de índices: 1 se o anafórico "ele" parece estar marcado pelo estado de ativação da unidade 1 , seu centro será o elemento que se encontra no primeiro lugar do conjunto dos centros antecipadores (Ca). Entretanto, se o pronome anafórico dêitico estiver marcado por um estado de ativação da entidade 2 , seu centro preferido será um elemento ordenado inferiormente no conjunto $\mathrm{Ca}$.

O aumento dos tempos de leitura, quando o pronome anafórico-dêitico se refere à entidade 2 em relação à 
referência feita à entidade 1 , ou quando um pronome anafórico-dêitico refere-se à entidade 1 em relação a uma referência realizada à entidade 2 (ver figura 2), parece claramente indicar que cada uma das duas expressões é marcada quanto ao estado de ativação de seu referente: o pronome "ele", estabelecendo o centro de atenção no foco mais elevado, agiria como um revelador do foco elevado. Um contraste ocorre com o pronome "este", ao estabelecer o centro de atenção sobre o foco médio: ele agiria principalmente como um compensador do foco médio.

A utilização do pronome anafórico-dêitico para o estudo da focalização das entidades discursivas contribui com alguns elementos novos para os princípios propostos pela teoria da centralização. De fato, um dos princípios dessa teoria é que o elemento mais saliente - mais focalizado - é o candidato preferido para uma menção posterior, em um enunciado seguinte. Esse princípio, validado por um efeito de penalidade do nome repetido, sugere também que os elementos de ordem superior no conjunto do Ca serão sempre os candidatos preferidos. Entretanto, para o pronome "este", o elemento preferido não é o mais saliente da lista.

Em outros termos, não existe um só centro preferido, mas sim, pelo menos um para o pronome anafórico (elemento fortemente focalizado) e pelo menos outro para o pronome anafórico-dêitico (elemento mediamente focalizado). Os experimentos envolvendo a teoria da centralização dificilmente podem apreender esta disposição de centros diferentes, quando a centralização só considera pronomes anafóricos e substantivos repetidos. Portanto, a generalidade da fórmula de ordenamento proposta pela centralização poderia ser questionada. Efetivamente, se uma entidade média focalizada é menos proeminente, menos acessível do que uma entidade com foco elevado, seria de se esperar que o pronome "este", de forma melhor do que o pronome "ele", permitisse recuperar uma entidade mediamente focalizada. Assim, fazer referência a uma entidade que é apenas um foco médio em relação a uma entidade fortemente focalizada provocará uma lentidão na leitura.

Em suma, nossa hipótese, ao prever que o pronome "este" constitui o meio capaz de mudar o foco do discurso atual (Cornish, 1999; Kleiber, 1994), quer dizer que ele permite desviar a atenção da entidade fortemente focalizada para tornar a entidade medianamente focalizada referencialmente saliente. Entretanto, os resultados obtidos indicam que o pronome "este" acessa o foco médio sem levar a um esforço de tratamento suplementar, ou seja, tão rápido quanto o pronome "ele" acessa o foco elevado. Isto sugere que uma entidade, ordenada inferiormente, não é, em si mesma, menos acessível.
O estabelecimento do foco de atenção sobre uma entidade medianamente focalizada passa por uma modificação real do foco de atenção atual? De fato, o emprego de termos como "modificar o foco de atenção do discurso atual" pressupõe um estado anterior já estabelecido, no caso, sobre a entidade mais focalizada. $\mathrm{Ou}$, se o foco de atenção é pré-estabelecido, o desvio do foco atencional deveria ocasionar um aumento de custos de tratamento, no sentido que, para aumentar a acessibilidade de uma entidade que é apenas um foco médio, é preciso elaborar um processo estratégico custoso em relação aos recursos de tratamento, que consiste em inibir a entidade atualmente focalizada no foco atencional para introduzir uma nova entidade (Engle, 1996). A partir dos resultados obtidos, a função do pronome "este" não deve ser mudar o foco de atenção atual mas estabelecer diretamente o foco de atenção sobre uma entidade medianamente focalizada.

A evidência de uma função específica do pronome "este", para estabelecer o centro de atenção sobre uma entidade medianamente focalizada, contrasta com a função do pronome anafórico "ele" que revela um foco elevado. Diferentemente do substantivo repetido, que é um marcador contrastivo do pronome anafórico utilizado pela teoria da centralização, o pronome "este" manifesta uma forte dependência da focalização de entidades discursivas. De fato, a forma de ordenamento das entidades do $\mathrm{Ca}$, proposta pela teoria da centralização, parece muito genérica. Esta fórmula, apoiada no estudo de dois marcadores com limitações diferentes (o substantivo repetido, diferentemente do pronome anafórico, não é sensível à focalização), poderia então ser questionada. Se, de fato, existem tantos centros preferidos quanto expressões referenciais sensíveis à focalização de entidade, ou seja, tantas formas de ordenar os elementos do Ca, então esta fórmula perde sua força teórica e pode tornar-se caduca.

\section{Referências}

Chambers, C. G. \& Smyth, R. (1998). Structural parallelism and discourse coherence: A test of centering theory. Journal of Memory and Language, 39, 593-608.

Cornish, F. (1999). Anaphora, discourse, and understanding. Evidence from English and French. Oxford: Clarendon Press.

Engle, R.W. (1996). Working memory and retrieval: An inhibition-resource approach. Em R.W. Engle (Org.), Working memory and buman cognition (pp. 89-120). Oxford: Oxford University Press.

Fossard, M. (1999). Traitement anaphorique et structure du discours. Etude psycholinguistique des effets du focus de discours sur la spécificité de deux marqueurs référentiels: le pronom anaphorique “il" et le nom propre répété. In Cognito, 15, 33-40. 
Garrod, S., Freudenthal, D. \& Boyle, E. (1994). The role of different types of anaphor in the on-line resolution in a discourse. Journal of Memory and Language, 33, 39-68.

Gordon, P. C., Grosz, B. J. \& Gilliom, L. A. (1993). Pronouns, names and the centering of attention in discourse. Cognitive Science, 17, 311-347.

Gordon, P. C. \& Chan (1995). Pronouns passives and discourse coherence. Journal of Memory and Language, 34, 216-231.

Gordon, P. C. \& Hendrick, R. (1998). The representation and processing of coreference in discourse. Cognitive Psychology, 22, 389-424.

Grosz, B. J., Joshi, A. K. \& Weinstein, S. (1995). Towards a computational theory of discourse interpretation. Computational Linguistics, 21, 203225

Hudson-D’Zmura, S. B. \& Tanenhaus, M. K. (1998). Assigning antecedents to ambiguous pronouns : The role of the center of attention as the default assignment. Em M. Walker, A. K. Joshi \& E. Prince (Orgs.), Centering in discourse (pp.199-227). Oxford: Oxford University Press.
Karmiloff-Smyth, A. (1980). Psychological processes underlying pronominalization and non-pronominalization in children's connected discourse. Em J. Kreiman \& A. E. Ojeda (Orgs.), Papers from a parasession on pronouns and anaphora (pp. 231-249). Chicago: Chicago Linguistic Society.

Kleiber, G. (1994). Anaphores et pronoms. Champs linguistiques. Louvain-LaNeuve: Editions Duculot.

Sanford, A. J., Moar, K. \& Garrod, S. C. (1988). Propers names as controllers of discourse focus. Language and Speech, 31, 43-56.

Walker, M., Joshi, A. K. \& Prince, E. (1998). Centering in naturally occuring discourse: An overview. Em M. Walker, A. K. Joshi \& E. Prince (Orgs.), Centering in discourse (pp.1-31). Oxford: Oxford University Press.

Recebido: $13 / 10 / 2000$

Revisado: 02/01/2001

Aceite final: 06/03/2001

Sobre os autores:

Marion Fossard é Fonoaudióloga, Doutoranda em Lingüística sob a direção do Prof. Dr. Jean-Luc Nespoulous no Laboratório de Neuropsicolíngüística da Universidade de Toulouse-le Mirail, Toulouse, França.

Dominique Cardebat é Doutora em Lingüística, pesquisadora do Iserm, Unidade 455, Hospital Purpan, Toulouse, França.

Jean-Luc Nespoulous é Diretor do Laboratório de Neuropsicolíngüística da Universidade de Toulouse-le Mirail e Diretor do Instituto Federativo de Ciências do Cérebro de Toulouse, IFR nº 96, Toulouse, França. 